\title{
Globalizing Urban Economies and Social Inequality: An Empirical Assessment. The Case of Amsterdam and Rotterdam
}

\author{
Jack Burgers and Jeroen van der Waal
}

\begin{abstract}
One of the key arguments in the grand narratives on globalization is that of time-space compression. Reflecting the discussion on the relations between globalization and inequality, this chapter argues that the most important local effect of the immensely increased mobility has been a process of fragmentation of cities. The chapter will focus on an empirical background on the changing international division of labour, which caused the deindustrialization of the advanced economies and consequently put the Keynesian welfare-state under heavy pressure; the spectacular growth in and use of communications technology, especially the internet; and the rapidly growing international mobility of people, both in the form of long distance migration and of international tourism. The chapter will elaborate the notion of the fragmentation of cities, using illustrations from the city of Rotterdam in the Netherlands.
\end{abstract}

\section{Globalization and Local Consequences: Attracting Capital and Urban Inequality}

The presence of internationally operating corporations is one of the main indications of urban competitiveness. By operating in an international, possibly even global arena, those forms of enterprise actually relate individual cities to the international economy at large. In a globalizing economy, nation-states are afraid to lose their competitive edge and strive for prominence in the world economy by attracting, supporting and catering to internationally operating corporations. That is why economically advanced nation-states in their spatial and urban policies currently focus on their strong, vital and prosperous cities and city regions, and make them as 'global' as possible, instead of compensating economically peripheral and relatively backward cities and regions, as was the case for much of the second half of the 20th century (cf. Sassen, 2001).

The international competitiveness of cities is also considered to be important for the improvement of the life chances of their inhabitants. The general idea is

\footnotetext{
J. Burgers

Department of Sociology, Erasmus University, Rotterdam, The Netherlands
} 
that a thriving urban economy, indicated by the city's attractiveness to international capital, ultimately will enhance the welfare and well-being of all living there. But the question is whether this neo-liberal perspective holds true and, if so, whether all people will profit from the globalizing economies of cities. Serious doubts have been formulated in this respect, particularly in the debate on 'global' or 'world' cities. 'Global' or 'world' cities are the most successful cities in attracting internationally operating firms and capital. In the most influential conceptions of 'global' or 'world'-cities (Sassen, 1991, 2001; Friedmann and Wolff, 1982), the social structure of those cities is a privileged, if not essential, issue. Because 'global' or 'world' cities $^{1}$ arguably have the most internationalized economies, they can be considered paradigmatic from a heuristic point of view. What is manifest and visible in those cities is expected to be the future of cities with a (still) less internationalized local economy (cf. Burgers, 1995, 2006). That would also be true for their emerging social structure: the actual social structure of 'global' or 'world' cities can be seen as the fate of all cities that succeed in becoming more attractive to international capital and internationally operating companies.

Friedmann (1986) explicitly has stated that 'the economic variable' is decisive for understanding the global city: global cities are used by 'global capital' as 'basing points' in the spatial organization and articulation of production and markets. The driving economic force is a limited number of rapidly growing sectors, particularly corporate headquarters, international finance, global transport and communications, and producer services. According to Friedmann (1986), the social structure of global cities is polarized, and because those cities attract many migrants, social polarization coincides to a large extent with ethnic fissures. From a policy perspective, the main problem with global cities is that, again according to Friedmann (1986), they generate more social costs than they raise sufficient taxes to pay for those costs.

Sassen $(1991,2001)$ stresses that economic globalization is essentially a centralized process of de-centralization, only made possible by information technology and the ascendancy of a number of cities that function as steering places, 'geographical cockpits', of an increasingly international economy. Like Friedmann, Sassen argues that the social structure of global cities is polarized, mainly along ethnic lines because global cities attract large numbers of migrants who find jobs at the lower end of the labour-market or in the informal economy.

Now, if Sassen and Friedmann and Wolff are right, national and local policies aimed at making cities more competitive by attracting global capital and internationally operating companies would create a problem of social justice because of the social polarization brought about by the globalization of the local economy. From an urban policy perspective it is therefore of the utmost importance to assess the social consequences of the globalization of urban economies.

\footnotetext{
${ }^{1}$ In the remainder of this chapter, we will only use the term 'global' city, referring to both Sassen's 'global city' and Friendmann's and Wolff's 'world city'. The difference between Sassen's and Friedmann's thesis is that Sassen seems to follow a more holistic line of reasoning, in which different aspects of globalization - economy, demography and culture - tend to be interrelated.
} 
Sassen's and Friedmann and Wolff's thesis is not undisputed. Critics of the thesis of the social polarization of global cities (cf. Hamnett, 1994, 1996; Waldinger, 1996) have argued that the job structure of cities in advanced economies is not polarizing, but upgrading. They agree that the number of jobs for which higher educational training is needed has been growing, but they claim that the number of jobs at the bottom of the labour-market has decreased rather than increased.

Another important criticism of the polarization thesis of Sassen and others relates to the influence of different types of welfare-states (cf. Esping-Andersen, 1990, 1993) on the labour market and social inequality. There is strong evidence that, in spite of the globalization of the economy, institutional differences between nationstates still play a substantial role as determinants of social inequality (cf. Burgers and Musterd, 2002). Richard Whitley (2000) goes even one step further and argues that one should not restrict the notion of 'institutional' factors to welfare-states which have to adapt to or mitigate global capitalism. He claims that there are not only divergent welfare-states, but, more important, also divergent 'capitalisms'. He shows that the three economic world regions - North America, Europe and the Far East - have different forms of capitalisms when one takes into account such variables as the role of government in the economy, the ownership of economic enterprises, the role of shareholders and personnel, relations between competing enterprises and between enterprises within the same production chain, et cetera. These differences at least suggest that economic globalization will not necessarily lead to the demise of the welfare-state or to increased inequality.

So, when it comes to the effects of the globalization of urban economies on social inequality, the criticism of the global city thesis first of all amounts to challenging the polarization thesis. Furthermore, it is argued that the effect of the globalizing economy is substantially 'filtered' by different types of welfare states and maybe even different types of 'capitalisms'. The latter point strongly suggests that research on social inequality in cities should take the institutional context into account. That is to say, that one should differentiate between different states and maybe even economic regions. That is a relatively easy thing to do. But in order to decide whether or not to accept the polarization thesis, one runs into a more fundamental problem, which is more difficult to solve: the problem of agency and, related to that, the question of the level of analysis.

In a convincing criticism of the major formulations of the global city thesis, Taylor (2004) has argued that most assertions about the nature and social makeup of global cities at closer scrutiny are not empirically substantiated. This is Short et al.'s (1996) 'dirty little secret' of the theory of global cities: most of the data used in the important theoretical statements are, at best, illustrations rather than empirical proof of the global city thesis, because the data used do not really pertain to the concepts used. In most cases, some kind of measure of the global character of a city is used on the one hand, and a measure of social inequality on the other. So when in a global city, say, income inequality is greater than in a less global city, this is used as proof of the thesis that global cities are socially polarized.

Most of the empirical literature criticizing the polarization thesis of global city theory suffers from the same flaw. When the income distribution in a global city 
is not polarized, the conclusion is that globalization does not cause polarization. In both cases, though, there is the problem of agency: exactly what makes a city a 'global' city? As Taylor (2004) has argued, the city - apart from being an administrative unit, a municipality - should not be reified and seen as an actor in itself. According to Taylor, cities become part of international networks through the agency of the international corporations located in those cities; economic actors thus connect cities to other cities.

We not only firmly agree with Taylor's line of reasoning, but want to carry his argument even one step further and argue that for the relationship between global city formation and social inequality, one should also look at the very agents that make a city a global city: internationally operating corporations. In other words, in order to answer the question of whether or not the globalization of urban economies leads to social inequality, one should first and foremost study the characteristics of enterprises that contribute to the globalization of urban economies instead of merely studying the characteristics of global cities at large.

This is what we will do in this chapter, focussing on the cities of Amsterdam and Rotterdam. In Section 2, we describe some general features of the economies of Amsterdam and Rotterdam. We show that the two cities have rather different labour market structures. Then, in Section 3, we change our perspective from the cities at large to their firms, corporations and different employers. One of the ways in which globally operating firms contribute to urban inequality is by their specific labour market structure which, allegedly (cf. Sassen, 1991, 2001), is polarized. So instead of looking at the labour market structure of the city at large, we present analyses on wage levels within individual firms and employers. In Section 4, we present our main conclusions in terms of both urban theory and urban policy.

\section{Amsterdam and Rotterdam: Labour-Market Opportunities for Different Groups}

Are Amsterdam and Rotterdam global cities? Global cities can be seen as 'binary things', that is to say 'real', essentialist 'to be, or not to be' entities. In her work on global cities Sassen (2006a: 315) has suggested that there are 'about forty' of those cities worldwide. In other instances though, Sassen has argued ${ }^{2}$ that the concept of the 'global city' can be conceived of as a heuristic perspective, simply meaning that one looks at those parts or sectors of local urban economies which are internationally oriented: '.. (the) global city is not a descriptive term meant to capture the whole city. It is an analytical construct that allows one to detect the global as it is filtered through the specifics of a place...' (Sassen, 2006a: x). In this chapter, we will, as a starting point, use the heuristic conception of the global city, which is dominant in empirical research on globalization and its consequences for individual

\footnotetext{
${ }^{2}$ For this ambiguity in Sassen's work on the global city, see: Burgers, 1995; Burgers and Van der Waal, forthcoming.
} 
cities (Burgers, 2006). We will be more specific about how we use the notion of the 'international orientation' of the cities under scrutiny later on. For a start, it suffices to say that both Amsterdam and Rotterdam have been part of more extensive studies of urban hierarchies and studies of global networks of international corporations. In Taylor's (2004) work on the interconnectedness of cities, Amsterdam is part of a set called 'gamma world cities', together with, among others, Boston, Melbourne, Prague. In Rotterdam, there is only 'some evidence' of global city formation, which is also the case for cities as Abu Dhabi, Oslo, Ho Chi Minh City, and Bogota (idem). Of course, those rankings are highly dependent on the data used to map these hierarchies, in this case, data referring to advanced producer services. The picture changes when one looks at the infrastructural gateway function of Rotterdam.

In The Netherlands, Amsterdam and Rotterdam are the main international gateways. Amsterdam is, first of all, an international gateway because of its airport, Schiphol, which, according to the number of passengers, ranked 10th worldwide in 2005 - Atlanta (Hartsfield-Jackson Atlanta International Airport) being the busiest and 4th in Europe - behind London, Paris and Frankfurt. Rotterdam is one of the biggest port-cities in the world. Worldwide, Rotterdam is 3rd in terms of tonnage of cargo, behind Shanghai and Singapore. Apart from its airport, Amsterdam also is a prominent European financial centre and by far the number one destination of international tourists visiting The Netherlands. ${ }^{3}$ In 2003, 435,100 foreign visitors spent a night in a hotel in Rotterdam. For Amsterdam that number was almost ten times larger: nearly 4 million $(3,985,000)$ nights spent by people coming from abroad. Amsterdam is clearly much more a service city than Rotterdam, at least when we look at the commercial services. Rotterdam is a manufacturing city. In both cities, about a third of the total employment consists of non-commercial services, mainly education, health and other public services. In the Dutch case - and in many other European continental welfare-states for that matter - the national and local state is heavily involved here, both in terms of financing and regulation. So, at least one third of the jobs are 'sheltered' from international competition.

Another way to conceive of local economic performance is to look at unemployment. What are the differences between Amsterdam and Rotterdam in terms of unemployment? Since the position of immigrants (and their descendents) in urban labour markets is an important element in theories on globalization's consequences for urban social inequality, we will compare unemployment rates for the main ethnic groups.

Table 1 reveals remarkable results. Apart from the indigenous Dutch, in terms of employment all groups do substantially better in Amsterdam than in Rotterdam.

\footnotetext{
${ }^{3}$ Other than Amsterdam and Rotterdam, The Netherlands only can boast of The Hague as a city with global city characteristics: it is not only the seat of government and therefore houses dozens of embassies, but, more important, The Hague hosts the International Court of Justice and therefore can be seen as the 'the legal capital of the world'. Interestingly enough, empirical research on global cities and international city networks tends to focus on either the headquarters of transnational corporations or advanced commercial producer services. Supranational institutions and the networks they are part of, tend to be relatively neglected.
} 
Table 1 Unemployment in different ethnic groups in Amsterdam and Rotterdam

\begin{tabular}{lcc}
\hline December, 2004 & Amsterdam & Rotterdam \\
\hline Gross unemployment rate & & \\
Dutch & 7.3 & 6.7 \\
Antillians & 8.1 & 15.8 \\
Surinamese & 7.2 & 10.8 \\
Moroccans & 8.9 & 14.5 \\
Turks & 10.0 & 15.3 \\
\hline
\end{tabular}

Source: CWI, Centrum voor Werk en Inkomen.

Unemployment rates for the main Dutch minority groups are between 1.5 and 2.0 times higher in Rotterdam than in Amsterdam.

In Table 2, we add the results for people with higher labour-market qualifications in terms of schooling.

Here, differences are basically insignificant. So the conclusion can be drawn that for members of minority groups without much schooling and professional training, Amsterdam offers much better job opportunities than Rotterdam. In theoretical terms, this is an interesting finding. Compared to Rotterdam, Amsterdam fits Sassen's model: a greater share of commercial, partly producer-services, seems to create extra jobs for people, such as many members of minority groups, who have a less than average education. Rotterdam seems to fit the upgrading model. In the recent past, many jobs were lost in traditional manufacturing industries, including the port. The remaining parts of the traditional industries have been upgraded, as can be clearly seen when we look at the automation and containerization of the harbour. Manual labour has diminished rapidly, and the commercial services do not compensate for that loss.

The risk we take in drawing a conclusion like this, based on a very general and rough comparison of Amsterdam and Rotterdam, becomes manifest when we take the national data on unemployment into account, as in Table 3.

When we look at this table, we see that the performance of Amsterdam is not that particular anymore. It seems that it is not so much the good record of Amsterdam,

Table 2 Unemployment within different ethnic groups according to educational level in Amsterdam and Rotterdam

\begin{tabular}{lcclll}
\hline December, 2004 & Amsterdam & Rotterdam & Amsterdam & Rotterdam \\
\hline $\begin{array}{l}\text { Gross } \\
\text { unemployment }\end{array}$ & & $\begin{array}{l}\text { Gross } \\
\text { unemployment rate, } \\
\text { rate }\end{array}$ & $\begin{array}{l}\text { people with academic } \\
\text { or professional } \\
\text { education }\end{array}$ & \\
Dutch & 7.3 & 6.7 & Dutch & \\
Antillians & 8.1 & 15.8 & Antillians & 2.6 & 1.0 \\
Surinamese & 7.2 & 10.8 & Surinamese & 0.5 & 0.4 \\
Moroccans & 8.9 & 14.5 & Moroccans & 0.5 & 0.7 \\
Turks & 10.0 & 15.3 & Turks & 0.5 & 0.7 \\
\hline
\end{tabular}

Source: CWI, Centrum voor Werk en Inkomen. 
Table 3 Unemployment in different ethnic groups in Amsterdam, Rotterdam and The Netherlands

\begin{tabular}{lccc}
\hline December, 2004 & Amsterdam & Rotterdam & Netherlands \\
\hline Gross unemployment rate & & & \\
Dutch & 7.3 & 6.7 & 3.9 \\
Antillians & 8.1 & 15.8 & 8.8 \\
Surinamese & 7.2 & 10.8 & 6.4 \\
Moroccans & 8.9 & 14.5 & 10.1 \\
Turks & 10.0 & 15.3 & 10.3 \\
\hline
\end{tabular}

Source: CWI, Centrum voor Werk en Inkomen.

but the poor record of Rotterdam which stands out. Apart from the indigenous Dutch, Rotterdam does worse than both Amsterdam and The Netherlands as a whole. Compared to The Netherlands, Amsterdam does not stand out - it is neither better nor worse. In comparison to the country at large, Amsterdam does not seem to produce more jobs for minority groups, as Sassen's global city theory would have it.

There might be a difference between Amsterdam and The Netherlands at large in terms of where exactly members of minority groups are employed. The share of employment in manufacturing industries in The Netherlands is larger than in Amsterdam. It could very well be that manufacturing industries are more important as employers for poorly educated workers outside the main cities, and commercial services more important in the cities. Rotterdam's poor performance would then be the result of the combination of two factors: it has lost industrial employment for poorly educated workers, and it has not compensated for this loss in term of the growth of jobs requiring only lower-level qualifications in the commercial service industries.

But again, these are more or less educated guesses; the data are on too high a level of aggregation to decide on this specific issue. In order to answer the question of whether the globalization of an urban economy leads to an increase or decrease of inequality, one has to study data at the level of individual firms in terms of their internal labour markets. This we will do in the next section.

\section{The Link Between Cities and the Global Arena: Internationally Operating Companies and Their Internal Labour Markets}

\subsection{Data and Operationalization}

Our analyses are based on the Dutch biannual 'OSA-labour demand panel' which started in 1989. The OSA Employers' survey is designed to allow more insight into the nature and size of demand for labour by organizations, as well as more particular factors concerning the demand for labour at the establishment level. The organizations are asked for detailed information concerning their product, production processes, the technologies used, their personnel, personnel policy and 
diverse financial and economic indicators. ${ }^{4}$ The panel consists of a random sample survey of employers with more than five employees. Data are gathered both by written questionnaires and interviews, both face-to-face and by telephone. Because many employers drop out with every new round of data collection, in every 'wave' new companies are randomly selected to complete the sample.

We will only use data of employers settled in the agglomerations of Amsterdam and Rotterdam. ${ }^{5}$ In order to have a substantial number of cases within those urban regions, we used five different waves of data collection - 1995, 1997, 1999, 2001 and 2003 - and combined them into one dataset. In doing so, we maximized the number of employers, without including employers more than once. ${ }^{6}$

Independent variables ${ }^{7}$ - in order to rank employers in terms of the degree in which they are part of the international economy, we used two variables. The first is the percentage of returns realized by exports. The second is a dichotomy, indicating whether employers experience foreign competition or not. These two variables are standardized and as such combined in a new variable, internationalization: ${ }^{8}$ a scale indicating the average score on the two constituting variables. In order to be able to compare Amsterdam and Rotterdam, we created a dummy variable city in which Amsterdam is coded as 1 and Rotterdam is coded as 2. The last set of independent variables consists of economic sector dummies: Industry, Commercial services and Non-commercial services.

Dependent variables - the impact of economic internationalization on the wage structure within companies is analyzed using two dependent variables: polarization and percentage of low-income employees. In each volume of the survey, employers were asked for the percentage of employees per income category. Each volume used either seven or eight income categories. The lowest income category is used for the variable percentage of low-income employees. The highest one (for volumes with seven categories) or two (for volumes with eight categories) income categories are considered high-income. ${ }^{9}$

\footnotetext{
${ }^{4}$ For more information see: http://www.tilburguniversity.nl/osa/datasets/-labour_demand_panel. html

${ }^{5}$ More specifically, we use the so-called 'COROP-area', which is an urban area based on a nodal classification principle. Each COROP-area has a central core (city) with a surrounding area measured by relations such as the traffic between place of residence and place of work of urban employees.

${ }^{6}$ In the COROP-areas of Amsterdam $(12,292)$ and Rotterdam $(11,826)$ there are $24,118(12,292+$ 11,826 ) companies with five or more employees (point of measurement 01-01-2005) This means it is necessary to have a sample size of at least 378 for a confidence interval of $5 \%$ and a confidence level of $95 \%$ for analyses. This proves to be no obstacle for the analyses in this chapter. Calculated on: http://www.surveysystem.com/sscalc.htm at 25-10-2006.

${ }^{7}$ All variables in the analyses have been standardized.

${ }^{8}$ A principal component analysis on these two standardized variables gives a first factor that explains $74 \%$ of the variance. The factor loadings of these variables are both 0.864 . A reliability analysis gives Cronbach's Alpha of 0.655 . This indicates a reasonable scale.

${ }^{9}$ It needs to be emphasized that the volumes do not always use the same category limits. To overcome possible invalid research findings because of this we will use year as a control variable (see below).
} 
The construction of the variable polarization needs some explanation. The notion of polarization has also been defined as the thesis of 'the declining middle': the middle-income stratum gets smaller while the low-income and high-income strata both increase. If they do not both increase, it would either be a case of upgrading the high-income stratum grows while the low-income stratum does not - or downgrading - the low-income stratum grows while the high-income stratum does not. To measure polarization we used the mean pair distant coefficient. ${ }^{10}$ This coefficient is able to measure income inequality in the form of pure polarization, leaving upgrading and downgrading out, which most measures of inequality fail to do.

Control variables - we will use year as a control variable because, as stated above, the data contain volumes of different years, while most often we do not measure the effect of the course of time - for instance in terms of economic up- and downturns. ${ }^{11}$ We also use company size - the number of employees - as a control variable. The categories '5-10', '10-20', '20-50', '50-100', '100-500' and 'more than 500 employees' have been recoded from 1 through 6 respectively. The open character of the last category and the big range of the penultimate category made us decide to 'reduce' this variable to a quasi interval level, instead of assuming means for each category.

\subsection{Differences in Exposure to the International Economy of Companies in Amsterdam and Rotterdam}

In this section we will try to establish whether the difference between the two urban economies has consequences for the international exposure of individual companies. $^{12}$

As we have shown, economically Amsterdam and Rotterdam strongly differ in character. Amsterdam is the ideal type of a post-industrial, service-centred economy - with many advanced producer services like finance - where Rotterdam is the ideal type of an industrial city because of its port and port-related economic activities like transport and logistics (see Fig. 1).

Using multiple regression analyses, ${ }^{13}$ we started with assessing whether Amsterdam and Rotterdam differ in the extent to which their employers are exposed

\footnotetext{
10 The polarization index - a mean pair distant coefficient - is calculated as follows: polarization index $=\left(\left(\right.\right.$ hwc $\left.^{*} 1 w c^{*} \operatorname{ABS}(1-3)\right)+\left(h_{w c}^{*} \operatorname{mwc}^{*} \operatorname{ABS}(1-2)\right)+\left(\mathrm{mwc}^{*} \mathrm{hwc} \mathrm{c}^{*} \mathrm{ABS}(2-1)\right)+$ $\left.\left(\mathrm{mwc} l \mathrm{wc}^{*} \mathrm{ABS}(2-3)\right)+\left(\mathrm{hwc} \mathrm{wwc}^{*} \mathrm{ABS}(3-1)\right)+\left(\mathrm{wc}^{*} \mathrm{mwc}^{*} \mathrm{ABS}(3-2)\right)\right) /\left((\mathrm{hwc}+\mathrm{mwc}+\mathrm{lwc})^{*}\right.$ $($ hwc + mwc+lwc)).

'hwc' indicates 'high wage category', 'mwc' indicates 'middle wage category' and 'lwc' indicates 'low wage category'.

${ }^{11}$ Furthermore, some variables - as income - are constructed by variables that differ (slightly) per volume when it comes to category limits, as we stated before.

${ }^{12}$ Since both cities are part of the same Dutch institutional setting where labour regulation and social policies are rather centralized and therefore do not differ substantially between municipalities, such differences in internationalization as there are, cannot be attributed to the institutional context. ${ }^{13}$ For the details of our analyses, see the appendix.
} 
Percentage of establishments per sector inAmsterdam 2004

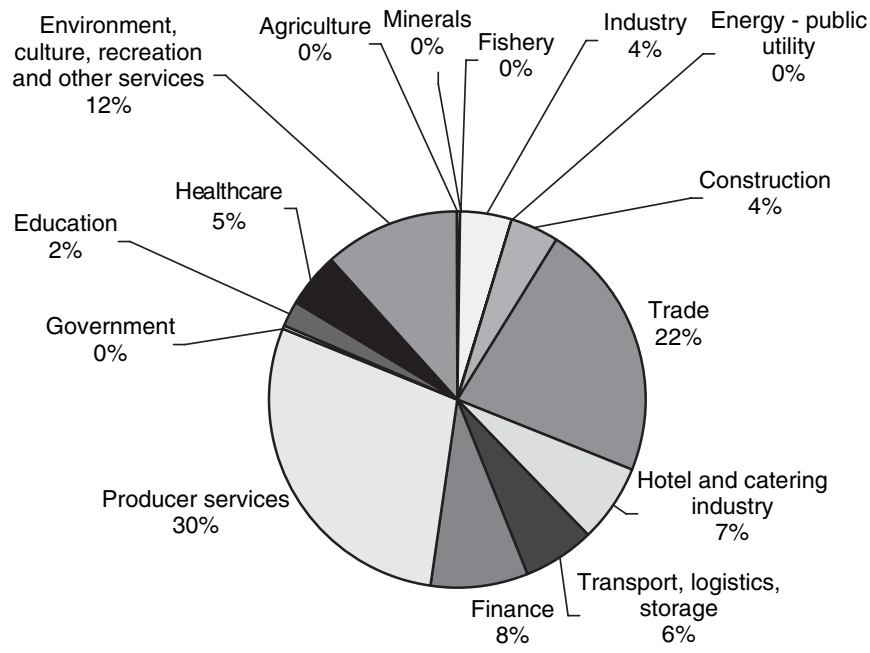

(a)

\section{Percentage of establishments per sector in Rotterdam 2004}

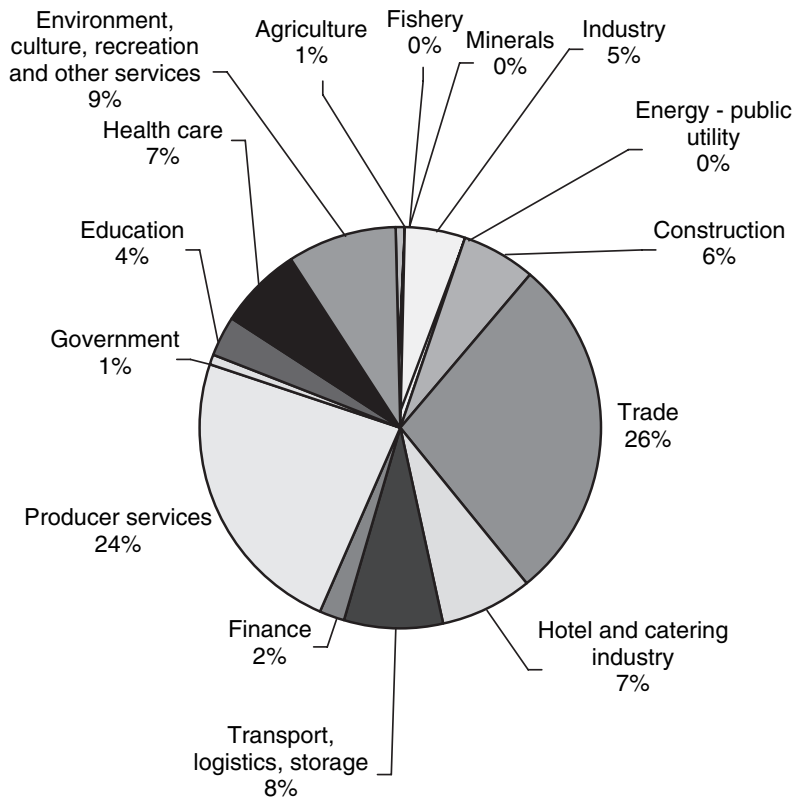

(b)

Fig. 1 Sector distribution in Amsterdam and Rotterdam in percentage of establishments and percentage of employees

(Source: Statistics Netherlands) 


\section{Percentage of employees per sector in Amsterdam 2004}

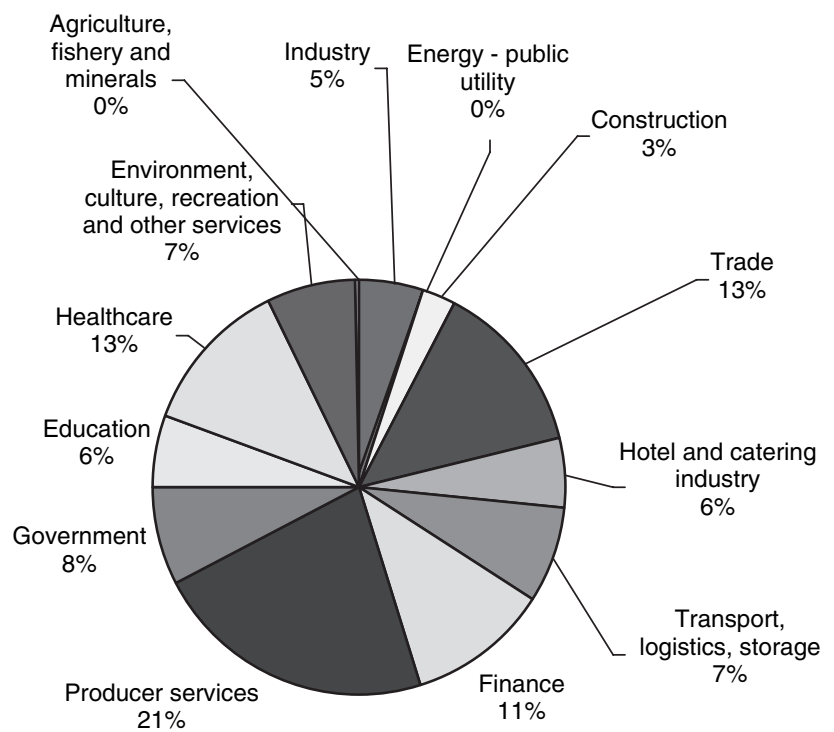

(c)

\section{Percentage of employees per sector in Rotterdam 2004}

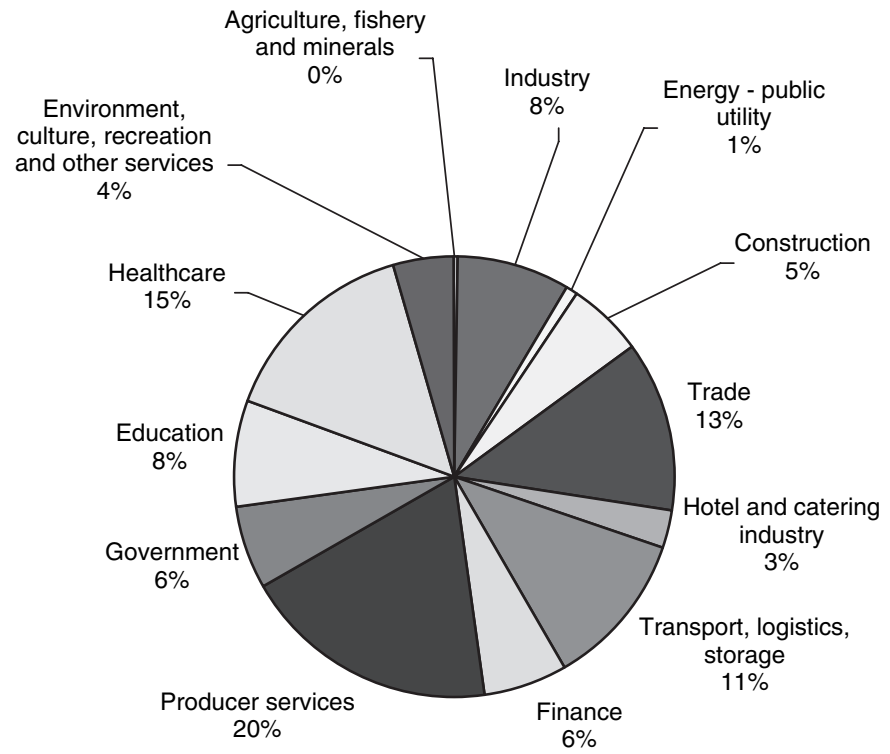

(d)

Fig. 1 (continued) 
to the international economy. The result of our analysis was that employers in Rotterdam are more exposed to the international economy than those in Amsterdam for at least two reasons. First, manufacturing industries are in general more internationally exposed than service industries. Because Rotterdam's economy is much more a traditional industrial one, it is more exposed than Amsterdam's economy. Secondly, Rotterdam's manufacturing industries turn out to be more internationally exposed than Amsterdam's manufacturing industries. Undoubtedly, Rotterdam's port is the main explanation here. It heavily dominates Rotterdam's economy, and its fate is almost completely dependent on international developments and competition.

This finding corroborates the part of global city theory, formulated by Sassen (1991, 2001), in which it is claimed that global cities are the new centres of control of the global economy. These cities determine the fate of other, less prominent cities (like Rotterdam), but are themselves not prone to international competition, since they are part of an interconnected set of cities with a complementary, collaborative rather than a competitive relationship. Our findings indicate that Amsterdam's and Rotterdam's economies are related to the global economy in different ways and thus the two cities face different forms of globalization of their local economies. Where Amsterdam scores high on the international interconnectedness emphasized by Taylor (2004), Rotterdam experiences much more international competition. This empirical finding has important theoretical and policy implications. As we stated before, empirical research addressing the global city thesis has particularly focused on the issue of polarization and social inequality. In this type of research, the concept of the global city has in many cases been used as a heuristic category, as we have also done at the start of our comparison of Amsterdam and Rotterdam. The problem, though, with using the concept as a heuristic device instead of as an essentialist category restricted to 'about forty' cities worldwide (Sassen, 2006b) is the role of international competition as it pertains to social inequality. In the essentialist version, global cities form a distinct set of basically not competing but, rather, strategically collaborating cities. If that is the case, their social structure may not be paradigmatic for other, internationally competing - i.e. non-global - cities, such as, for instance, Rotterdam.

The issue of international competition is an important one in the economic literature on globalization and wage inequality in which it is suggested that international competition is the key variable. The main argument is that increasing international competition leads to an upgrading of the job and wage structure in advanced economies. An increasingly knowledge-based and technologically innovative production, needed to stay ahead in international competition with low-wage countries, is seen as the cause for this upgrading. The question is what, in terms of wage-structure, the differences are - if any - between cities which (have to) compete internationally, such as Rotterdam, and those which don't - presumably global cities such as Amsterdam. There are two different logics of globalization involved here, possibly with different outcomes in terms of social inequality (cf. Burgers and Van der Waal, forthcoming). 
Since we aim at assessing the consequences of globalization of urban economies for social inequality in this chapter, the question then is what are the consequences in terms of social inequality of those two different logics of globalization of local economies.

\section{Internationalization and Social Inequality: The Examples of Amsterdam and Rotterdam}

As we stated before, the impact of internationalization or globalization on local economies, especially urban labour markets, is a central theme in the field of urban studies. It has been argued that global cities are characterized by a polarized income distribution (Sassen, 1991, 2001). Others (Waldinger, 1996; Hamnett, 1996) have claimed that urban labour markets of global cities have been upgrading instead of polarizing. Apart from this discussion, it is important to ask what the labour market opportunities are in non-global, manufacturing and internationally exposed cities such as Rotterdam. These different forms of globalization may have different outcomes when it comes to social inequality. Using the OSA data and applying multiple regression analyses, ${ }^{14}$ we assessed the consequences of economic restructuring and exposure to the international economy for wage inequality in companies in both cities, and, as far as possible, for the total number of workers in these cities.

Commercial services have the most polarized income structure, non-commercial services the least. In other words: the more prominent commercial services are in a local economy, the more polarized the income structure will be. This is in line with the global city-thesis, in which advanced producer services play an important role (cf. Sassen, 2001). Surprisingly enough, this difference between sectors does not explain the more polarized income structure of companies in Amsterdam in comparison to companies in Rotterdam. Overall, companies in Amsterdam have a more polarized income distribution than companies in Rotterdam. Company size is not significant: there is no relationship between the number of people employed in a company and the extent to which the income distribution is polarized. Since the companies in the analysis can be considered to be a random sample of all employers in Amsterdam and Rotterdam, this indicates that labour in Amsterdam has a more polarized wage structure than labour in Rotterdam. In short: economic restructuring leads to polarizing tendencies; increasing exposure to the international economy does not.

As indicated before, empirical research suggests that global cities are characterized by labour-markets and income distributions which are upgrading rather than polarizing. In order to decide on this issue using our data, we assessed the impact of internationalization on the share of low-income employees. We found that the share of low-income workers in the labour-market of Rotterdam is larger than in the

${ }^{14}$ See the appendix. 
labour-market of Amsterdam. Overall, employers in commercial services have more low-income workers than manufacturing companies and non-commercial services. Interestingly, although commercial services employ more low-income workers, and Amsterdam has a larger share of commercial services than Rotterdam, the latter city still seems to employ more low-income workers than Amsterdam.

The more a company is internationally exposed, the smaller its share of low-income employees. This makes sense: internationally exposed companies in advanced economies cannot compete on labour costs, but only by substituting machinery for labour or realizing higher product quality by using more expensive, professional labour.

The question remains: what is the impact of economic restructuring and exposure to the international economy for all workers in the cities under scrutiny. Growing employment in the commercial services sector and decreasing employment in the manufacturing industries leads to more low-income jobs in both Amsterdam and Rotterdam, while increasing exposure to the international economy leads to fewer low-income jobs. But, these processes do not explain the higher share of low-income workers in Rotterdam overall. If economic restructuring and increasing international exposure were the causes of the differences between Amsterdam and Rotterdam, the differences should have been just the opposite of our findings: fewer low-income workers in Rotterdam than in Amsterdam. Most likely, the explanation is to be found on the supply-side of the labour market: the Rotterdam labour force is on the average less schooled than the Amsterdam labour force, as Table 4 clearly shows.

Whereas in Amsterdam - and the other main Dutch cities for that matter - highly skilled jobholders outnumber workers with only basic schooling, in Rotterdam the opposite is true.

It is time to summarize the main outcomes of the analyses in this section on the income distribution in different forms of employment in Amsterdam and Rotterdam and for all workers employed in the two cities.

First, in line with the global city thesis, employment in Amsterdam has a more polarized wage structure than employment in Rotterdam. One would expect that the main cause for this difference is the dominance of commercial services, which are characterized by a relatively polarized income distribution, in Amsterdam. But surprisingly enough, this is not the case. Although the income structure of commercial

Table 4 Educational level Amsterdam and Rotterdam labour force

\begin{tabular}{lccll}
\hline & $\begin{array}{l}\text { Basic } \\
\text { training }\end{array}$ & $\begin{array}{l}\text { Academic or } \\
\text { professional } \\
\text { training }\end{array}$ & Difference & $\begin{array}{l}\text { Ratio } \\
\text { Basic/Academic or } \\
\text { professional }\end{array}$ \\
\hline $\begin{array}{l}\text { Amsterdam } \\
1996\end{array}$ & 99,000 & 164,000 & $+65,000$ & 0.60 \\
2002 & 101,000 & 202,000 & $+101,000$ & 0.50 \\
Rotterdam & & & & \\
1996 & 119,000 & 91,000 & $-28,000$ & 1.31 \\
2002 & 135,000 & 115,000 & $-20,000$ & 1.17 \\
\hline
\end{tabular}

Source: Statistics. 
services is more polarized than that of the manufacturing industries, this is not the cause of the more polarized income structure of Amsterdam companies compared to those in Rotterdam.

Second, total employment in Amsterdam counts fewer low-income workers than it does in Rotterdam. This difference cannot be explained by differences in sectorial composition or by international exposure. Exposure to the international economy leads to a smaller share of low-income workers, while economic restructuring leads to a higher share of low-income workers. Since Amsterdam is more post-industrial and its economy is less internationally exposed, one should expect that Amsterdam would have more low-income employees - not fewer.

At the beginning of Section 3.3, we have posed the question of whether differences in the globalization of urban economies have consequences for labour demand and social inequality. In answering these questions, we distinguished between two different aspects of globalization: global city formation (Amsterdam) and increasing international exposure of urban economies (Rotterdam). Our main conclusion is that, when it comes to wages and income distribution, both the differences between employment in Amsterdam and Rotterdam and those between the workers within those cities cannot be explained by these two different forms of globalization or internationalization of the economy. So, although the mechanisms or at least the processes described in global city theory are corroborated by our data, there is also a strong, independent effect related to specific differences between the two cities, and probably more in particular to differences between their labour supplies - a factor neglected by global city theory (cf. Waldinger, 1996).

\section{Conclusions}

What do our analyses tell us about globalization and social inequality at the local level? Does a successful policy of increasing the competitiveness of cities by making them more attractive to global capital, lead to less or more social inequality?

First, one should be aware of different forms of globalization or economic internationalization. Companies in the industrial sector are more exposed to the international economy than companies in the commercial services. So, paradoxically, the more 'global' a city is according to the global city literature - urban economies dominated by advanced producer services - the less its companies are internationally exposed. If one wants to assess the impact of economic internationalization on urban social inequality, one needs to take these different dimensions into account. Internationally exposed companies are characterized by upgrading and relatively few low-wage jobs, whereas advanced producer services are characterized by a more polarized wage structure. In general, global cities provide more jobs for workers with little schooling than do non-global cities. In other words, global cities provide more labour-market opportunities for workers without much schooling than nonglobal cities in which they will be more frequently faced with unemployment. Our data - Tables 1 to 3 - show this clearly for members of ethnic minority groups who 
are doing much worse in Rotterdam than in Amsterdam and in The Netherlands as a whole.

Secondly, one has to differentiate between economic restructuring - decreasing employment in the manufacturing industries and increasing employment in the service industries - on the one hand and international exposure on the other. Economic restructuring seems to cause a more polarized income distribution within cities because companies in the commercial service sector have a more polarized income structure than companies in the industrial sector. This is not a very sensational finding since it is consistent with many other studies on urban social inequality. But, the other dimension of economic internationalization that is under scrutiny here exposure to the international economy - seems to lead to a more upgraded income structure within cities because a stronger international exposure leads to a smaller share of low income employees. What is important to emphasize here is that economic restructuring and international exposure - two aspects many times implicitly or explicitly considered to be strongly interrelated - have different effects on income structure. These effects even partly cancel each other out.

Thirdly, in the literature on global cities the impact of economic internationalization seems to be seriously overstated. The specific historically grown character of cities seems to have a substantial impact on income distribution. We selected Amsterdam and Rotterdam for our analysis because of their fundamentally different economic characters. They indeed differ in terms of income polarization, the share of low-income and high-income workers in their companies and total labour force, but economic restructuring and exposure to the international economy do not explain these differences.

The problem of overstating the effect of globalization is especially clear when we take into account the apparently contradictory research findings at different levels of aggregation. We found that the more companies are exposed to the international economy, the smaller their share of low-income employees will be. This would then easily lead to the expectation that employers in Rotterdam - a city in which companies are more strongly exposed to the international economy than are companies in Amsterdam - would have a smaller share of low income workers than employers in Amsterdam. But our analyses show that exactly the opposite is true: Rotterdam employers have a larger share of low-income workers. The same kind of reasoning applies to the impact of economic restructuring on urban inequality. Economic restructuring as such leads to a more polarized income structure. Since Amsterdam clearly is more post-industrial, this would lead to the expectation that Amsterdam employers show a more polarized income structure than do businesses in Rotterdam. This expectation is confirmed by our analyses, but sector distribution is not responsible for this. Apparently, economic internationalization has not only different and even partly contrary effects on social inequality, but also its impact on urban social inequality is small compared to the impact of the historically grown character of a city and more specifically its labour supply.

In terms of urban policy, these findings lead to the highly important conclusion that while making a city more competitive in the global economy may be relevant for many reasons, the characteristics and potentials of the local labour supply seem to be more important when it comes to urban social inequality. Improving the capacities 
and qualifications of local labour and thus the social composition of cities seems to be more important in redressing urban social inequality than globalizing the urban economy per se.

Fourthly and finally, even in an era of globalization, substantial and maybe even increasing parts of urban economies are still locally oriented. Arguably, globalization leads to an increasing number of jobs that cater to local needs and locally based customers. In terms of trying to find employment for that part of the local population with poor labour market qualifications, this seems to offer positive opportunities because one could assume that locally tied employers - especially non-commercial services - will be more compliant with involvement in employment schemes for the unemployed than employers with no strong local ties and more exit-options.

\section{Appendix}

To increase the readability of this chapter, we decided to just summarize our findings from the regression analyses in the main text and to show the detailed tables in this appendix for reasons of controllability. Regression coefficients estimate the linear correlation between the dependent and one or more independent variable. Since all variables in the analyses are standardized, the highest possible scores are 1 - indicating complete linear correlation between the dependent and independent variable: the rise in one unit of the latter leads to a rise in one unit of the former, - or $-1-$ indicating a complete linear correlation as well, except now a rise in one unit of the latter leads to a decline in one unit of the former. The lowest score is 0 of course, indicating there is no linear correlation whatsoever.

In all tables we followed the same logic. First we checked whether companies in Amsterdam and Rotterdam differ by regressing the city dummy on the independent variable. Second, we regressed sector dummies on exposure to international competition (Table 5), and sector dummies and exposure to international competition on polarization (Table 6), and percentage of low-income workers (Table 7) to estimate their impact and to assess whether these impacts are responsible for the differences between Amsterdam and Rotterdam. For example: in Table 5, model 2 we see that companies in manufacturing are most strongly exposed to international competition, followed by companies in the commercial services, as compared to organisations in the non-commercial services. Since the coefficient of the city dummy declines in strength compared to model 1 - and falls into insignificance - this higher exposure of companies in manufacturing proves responsible for the difference in exposure to international competition between companies in Amsterdam and those in Rotterdam overall.

In Tables 5 and 6 we included a last model (model 4) in the analyses for estimating the impact on all employees in the cities under scrutiny. We regressed interaction effects of variables proven relevant in former models with company size. Since all interaction effects in these models are insignificant, company size proved to be irrelevant, indicating the estimated effects in former models are the same for all companies, no matter their size. 
Table 5 Regression analyses. Dependent variable is internationalization (method: ordinary least squares)

\begin{tabular}{llll}
\hline & Model 1 & Model 2 & Model 3 \\
\hline Independent variables & & & $\beta$ \\
City dummy (Rotterdam) & $\beta$ & $\beta$ & 0.049 \\
Manufacturing & $0.067^{*}$ & 0.047 & $0.347^{* * *}$ \\
Commercial services & & $0.352^{* * *}$ & $0.318^{* * *}$ \\
Non commercial services (ref.) & & $0.316^{* * *}$ & 0 \\
Industry $\times$ Rotterdam & 0 & $0.059^{*}$ \\
Commercial services $\times$ Rotterdam & & 0.034 \\
Control & & & \\
Company size & & & $0.190^{* * *}$ \\
& $0.158^{* * *}$ & $0.189^{* * *}$ & \\
$\mathrm{R}^{2}$ & & & 0.142 \\
$\mathrm{~N}$ & 0.030 & 0.141 & 1305 \\
\hline$* \mathrm{p}<0.05 ; * * \mathrm{p}<0.01 ; * * * \mathrm{p}<0.001$. & 1305 & 1305 &
\end{tabular}

Analyses of the OSA labour demand panels 1995, 1997, 1999, 2001 and 2003 with companies based in the COROP-areas Amsterdam en Rotterdam.

Table 6 Regression analyses. Dependent variable is polarization in income distribution (method: ordinary least squares) ${ }^{\mathrm{a}}$

\begin{tabular}{|c|c|c|c|c|}
\hline & Model 1 & Model 2 & Model 3 & Model 4 \\
\hline \multicolumn{5}{|l|}{ Independent variables } \\
\hline & Companies & Companies & Companies & $\begin{array}{l}\text { Urban } \\
\text { employees }\end{array}$ \\
\hline & $\beta$ & B & B & $\beta$ \\
\hline City dummy (Rotterdam) & $-0.068^{*}$ & $-0.066^{*}$ & $-0.065^{*}$ & $-0.071^{*}$ \\
\hline Industry (ref.) & & 0 & 0 & 0 \\
\hline Commercial services & & $0.089^{*}$ & $0.084^{*}$ & 0.071 \\
\hline Non commercial services & & $-0.104^{* *}$ & $-0.121^{* *}$ & $-0.124^{* *}$ \\
\hline Internationalization & & & -0.045 & -0.040 \\
\hline Commercial services $\times$ Company size & & & & -0.063 \\
\hline Non commercial services $\times$ Company size & & & & 0.007 \\
\hline \multicolumn{5}{|l|}{ Control variables } \\
\hline Year & $-0.069^{*}$ & -0.056 & -0.057 & -0.051 \\
\hline Company size & -0.052 & -0.038 & -0.030 & -0.016 \\
\hline $\mathrm{R}^{2}$ & 0.006 & 0.033 & 0.033 & 0.034 \\
\hline $\mathrm{N}$ & 612 & 612 & 612 & 612 \\
\hline
\end{tabular}

${ }^{*} \mathrm{p}<0.1 ;{ }^{* *} \mathrm{p}<0.05 ;{ }^{* * *} \mathrm{p}<0.01 ;{ }^{* * *} \mathrm{p}<0.001$.

${ }^{a}$ Since questions on the income distribution in the survey have many missing values, the number of companies that remains for analyses is less than half of the initial analysis on internationalization. Therefore, we consider it justified to use the 10 percent significance level. 
Table 7 Regression analyses. Dependent variable is percentage of low-income employees (method: ordinary least squares)

\begin{tabular}{|c|c|c|c|c|}
\hline & Model 1 & Model 2 & Model 3 & Model 4 \\
\hline \multicolumn{5}{|l|}{ Independent variables } \\
\hline & Companies & Companies & Companies & $\begin{array}{l}\text { Urban } \\
\text { employees }\end{array}$ \\
\hline & $\beta$ & $\mathrm{B}$ & $\beta$ & $\beta$ \\
\hline City dummy (Rotterdam) & $0.070^{*}$ & $0.073^{*}$ & $0.078^{* *}$ & $0.069^{*}$ \\
\hline Industry (ref.) & & 0 & 0 & 0 \\
\hline Commercial services & & $0.103^{* *}$ & $0.086^{*}$ & 0.074 \\
\hline Non commercial services & & -0.079 & $-0.128^{* *}$ & $-0.124^{* *}$ \\
\hline Internationalization & & & $-0.135^{* * *}$ & $-0.125^{* * *}$ \\
\hline Commercial services $\times$ Company size & & & & -0.056 \\
\hline Non commercial services $\times$ Company size & & & & 0.075 \\
\hline Internationalization $\times$ Company size & & & & 0.028 \\
\hline \multicolumn{5}{|l|}{ Control variables } \\
\hline Year & -0.024 & -0.014 & -0.017 & -0.004 \\
\hline Company size & $-0.262^{* * * *}$ & $-0.248^{* * * *}$ & $-0.224^{* * * *}$ & $-0.179^{* * * *}$ \\
\hline $\mathrm{R}^{2}$ & 0.068 & 0.041 & 0.105 & 0.113 \\
\hline $\mathrm{N}$ & 612 & 612 & 612 & 612 \\
\hline
\end{tabular}

${ }^{*} \mathrm{p}<0.1 ;{ }^{* *} \mathrm{p}<0.05 ;{ }^{* * *} \mathrm{p}<0.01 ;{ }^{* * * *} \mathrm{p}<0.001$.

Analyses of the OSA labour demand panels 1995, 1997, 1999, 2001 and 2003 with companies based in the COROP-areas Amsterdam en Rotterdam. 